\title{
Clinical characteristics of Coronavirus Disease 2019 outside Wuhan and development of early risk stratification tool
}

\section{Yucai Hong}

Department of Emergency Medicine, Sir Run Run Shaw Hospital, Zhejiang University School of Medicine Jianping Huang

Departments of Infectious Disease, Wenzhou Central Hospital

\section{Dong Chen}

Departments of Infectious Disease, Wenzhou Central Hospital

\section{Yinghai Ye}

Departments of Infectious Disease, Wenzhou Central Hospital

\section{Feifei Su}

Departments of Infectious Disease, Wenzhou Central Hospital

\section{Jianyi Dai}

Department of Infectious Disease, Wenzhou Central Hospital

\section{Jichan Shi}

Departments of Infectious Disease, Wenzhou Central Hospital

\section{Chaochao Shao}

Departments of Infectious Disease, Wenzhou Central Hospital

\section{Zhongheng Zhang ( $\nabla$ zh_zhang1984@zju.edu.cn )}

Department of Emergency Medicine, Sir Run Run Shaw Hospital, Zhejiang University School of Medicine

\section{Research Article}

Keywords: COVID-19, novel coronavirus, clinical characteristics, cost, prediction, length of stay

Posted Date: March 25th, 2020

DOl: https://doi.org/10.21203/rs.3.rs-19481/v1

License: (c) (i) This work is licensed under a Creative Commons Attribution 4.0 International License. Read Full License 


\section{Abstract}

Importance: Clinical characteristics of coronavirus disease 2019 (COVID-19) outside Wuhan are not well described, and there is no risk stratification tool for the prediction of COVID-19 outcome.

Objective: To describe the clinical characteristics of COVID-19 outside Wuhan and to develop a risk stratification tool for early risk stratification.

Design, Setting, and Participants: Single center, retrospective observational study conducted at Wenzhou, Zhejiang province (January 2020-February 2020) that included 140 patients with confirmed COVID-19. Clinical characteristics were described. A multivariate regression model was built to predict the risk of length of stay in hospital > 20 days (ProLOS). The last patient visit was on February 23, 2020.

Interventions: None

Main Outcomes and Measures: The primary outcome was ProLOS. Other outcomes included conversion to negative nucleic acid test, date of hospital discharge, vital status at discharge.

Results: A total of 140 patients were included during the study period. Lower lymphocyte count (1.0 [0.7, $1.3]$ vs. $1.3[0.9,1.72] \times 109 / L ; p=0.008)$, lower ionized sodium $(136[134.6,137.83]$ vs. $138[135.28$, $140.03] \mathrm{mmol} / \mathrm{L} ; \mathrm{p}<0.001)$ and higher PaCO2 (40.82 \pm 3.96 vs. $38.48 \pm 5.48 \mathrm{mmHg} ; \mathrm{p}=0.007)$ were associated with higher risk of ProLOS. The median time from hospital admission to the first negative nucleic acid test was 13 days (7.25 to 17 days). There were 4 (3\%) critically and 5 (4\%) severely ill patients. A multivariate model included predictors of age, time from contact to confirmation, DBP, lymphocyte count, AST, ionized sodium, $\mathrm{PaCO} 2$ showed good calibration and discrimination with an AUC of $81.6 \%$ (95\% Cl: $74.4 \%$ to $88.8 \%)$.

Conclusions and Relevance: The study described clinical characteristics of COVID-19 outside Wuhan. The major difference of COVID-19 in other cities included low comorbidity burden, low prevalence of severe or critical cases and low mortality rate. The risk stratification tool can be used for medical decision making and resource allocation.

Authors Yucai Hong and Jianping Huang contributed equally to this work and are co-first authors.

\section{Introduction}

Novel coronavirus disease 2019 (COVID-19) is caused by the severe acute respiratory coronavirus 2 (SARS-CoV-2), which has become a global health emergency due to its human-to-human transmission and the large number of confirmed cases in China and all over the world ${ }^{1}$. China is now taking strenuous efforts to combat this epidemic, which showed significant effect that the overall newly confirmed cases declined steadily. The most affected region in China is Wuhan, Hubei province, with the number of confirmed cases reaching above 47,000 on February $26,2020^{2,3}$. There have been many clinical studies describing the clinical characteristics of COVID-19 in Wuhan ${ }^{4-8}$. The cases ranged from mild to severe, 
and even death. The mortality rate is estimated to be around $2 \%$. The clinical onset can be atypical, with only half of the patients reported to have fever ${ }^{9,10}$. However, the report outside Wuhan is still rare ${ }^{11}$. There has been evidence showing that the clinical course of COVID-19 from outside Wuhan can be different from that from Wuhan ${ }^{12}$. For example, the crowdsourcing data from epidemic monitoring center showed that the mortality rate in other regions is much lower than that in Wuhan ${ }^{13}$. The first aim of the study was to describe clinical characteristics of COVID-19 outside Wuhan city.

Another important issue in managing COVID-19 is early risk stratification. To the best of our knowledge, there is no prediction tool for the prediction of clinical outcome for COVID-19. The development of a prediction tool can assist medical decision making and resource allocation. Since the majority of our patients were mild, we employed length of stay in the hospital as the primary end point. A multivariate model was developed to predict patients who were at risk of prolonged length of stay ( $>20$ days) in the hospital (ProLOS).

\section{Methods}

\section{Study design and setting}

The study was conducted in a tertiary care hospital in Wenzhou, Zhejiang province from January 15 to February 24, 2020. The hospital was a designated hospital for the treatment of COVID-19. Medical records of all patients with confirmed COVID-2019 were retrospectively reviewed. All patients were followed up until February 24, 2020. Patients were divided into two groups according to whether they were stayed in the hospital for longer than 20 days or not. Those with hospital LOS $>20$ days were classified as the ProLOS group, and those discharged hospital before 20 days were classified into the non-ProLOS group.

Baseline demographic and clinical characteristics were compared between the two groups. A multivariate regression model was built to predict the risk of ProLOS. The study was approved by the ethics committee of Wenzhou Central Hospital (NL2020-01-011) and was conducted in accordance to the Helsinki Declaration. Informed consent was waived by the institutional review board due to retrospective nature of the study. The study was reported according to the STROBE checklist ${ }^{14}$.

\section{Participants}

According to the General Office of National Health Committee, suspected cases were defined with clinical features and epidemiological risk. The clinical features included fever, imaging features of pneumonia, normal or reduced white blood cell count, or reduced lymphocyte count in the early stages of the disease onset. The epidemiologic risks included 1) a history of travel to or residence in Wuhan city, China or other cities with continuous transmission of local cases in the last 14 days before symptom onset; 2) contact with patients with fever or respiratory symptoms from Wuhan city, China or other cities with continuous transmission of local cases in the last 14 days before symptom onset; or 3 ) epidemiologically connected 
to SARS-CoV-2 infections or clustered onsets. Suspected cases who also fulfilled the following pathogenic evidence was considered as confirmed cases: (1) positive for the 2019-nCoV by the real-time PCR test for nucleic acid in respiratory or blood samples; 2) viral gene sequencing shows high homogeneity to the known SARS-CoV-2 in respiratory or blood samples ${ }^{15}$. Patients were excluded if 1) they had signed do-not-resuscitate order; 2) had severe burn or trauma and 3) end-stage malignancy.

\section{Variables}

Variables related to demographics, signs and symptoms, comorbidities, laboratory findings, complications and clinical outcomes were extracted from electronic medical records in a standardized case report form (CRF). Medical history included the date of the first contact with infection source, the suspected infection source, the time from contact to diagnosis.

Comorbidities included hypertension, diabetes mellitus, chronic kidney disease (CKD), chronic liver disease, cardiovascular disease, chronic pulmonary disease and malignancy. Clinical signs and symptoms included cough, fever, rhinorrhea, fatigue, anorexia, pharyngalgia, myalgia, headache, abdominal pain, vomiting and diarrhea. Laboratory tests included blood routines, biochemical profiles, electrolytes, coagulation profile and procalcitonin. Clinical complications included liver failure, respiratory failure, progression to severe or critical cases. Treatment included mechanical ventilation, oxygen therapy, and non- invasive mechanical ventilation.

The clinical outcomes included conversion to negative nucleic acid test, date of hospital discharge, vital status at discharge. LOS in the hospital was defined as the difference between hospital discharge and admission. For those stayed in the hospital on February 24, 2020, they were censored at that day. The censoring was considered to be non-informative (i.e. random censoring) that it would not bias the stochastic distribution of the hospital LOS.

\section{Statistical analysis}

Descriptive analyses were performed for all variables for our cohort. The comparisons between ProLOS and non-ProLOS groups were performed with standard methods. Normal quantitative data were expressed as mean and standard deviation (SD) and were compared using $t$ test. Skewed variables were expressed as median and interquartile range (IQR) and were compared using rank-sum test. Qualitive data were expressed as the number and percentage and were compared between groups using Chisquare test or Fisher's exact test as appropriate. The CBCgrps package was used for the analyses ${ }^{16}$.

Variables with $p<0.1$ in univariate analysis were included to build a full model. Then the stepwise model selection was performed by Akaike Information Criterion (AIC), aiming to obtain a model with lowest AIC

17. The model performance was assessed using discrimination and calibration. An area under curve (AUC) of greater than $80 \%$ was considered as good for clinical utility. The use of the model was 
demonstrated using nomogram ${ }^{18}$. All statistical analyses were performed using $\mathrm{R}$ (version 3.6.1). A conventional $p$ value less than 0.05 were considered as statistical significance.

\section{Results}

\section{Participants}

A total of 140 patients were included during the study period. No subjects were excluded due to prespecified exclusion criteria. Sixty-four (45.7\%) of the 140 patients had stayed in the hospital for more than 20 days (the ProLOS group).

\section{Baseline characteristics}

There was no difference between ProLOS and non-ProLOS groups in age, gender, epidemiological history and most comorbidities (Table 1). The ProLOS group showed significantly less days from contact to confirmation (median [IQR]: $6.5[4,9.25]$ vs. $7.5[5,14]$ days; $p=0.026)$. There was greater proportion of patients with malignancy in the ProLOS group ( $3 \% \mathrm{vs.} 0 \% ; p=0.041)$. Most patients showed normal vital signs on admission. Interestingly, patients in the ProLOS group had higher SBP $(131[120,147]$ vs. 126 $[118,134] \mathrm{mmHg} ; \mathrm{p}=0.037)$ and $\mathrm{DBP}(86.41 \pm 11.21 \mathrm{vs} .80 .17 \pm 10.76 \mathrm{mmHg} ; \mathrm{p}=0.001)$. A large proportion of patients had abdominal symptoms on admission (39\%).

\section{Table 1 Baseline characteristics of patients and comparisons between ProLOS and non- ProLOS groups}




\begin{tabular}{|c|c|c|c|c|}
\hline Variables & $\begin{array}{l}\text { Total }(n= \\
140)\end{array}$ & $\begin{array}{l}\text { Non-ProLOS } \\
(\mathrm{n}=76)\end{array}$ & $\begin{array}{l}\text { ProLOS }(\mathrm{n}= \\
64)\end{array}$ & $\mathrm{p}$ \\
\hline Age, Mean \pm SD & $45.66 \pm 14.1$ & $47.44 \pm 15.42$ & $\begin{array}{l}43.54 \pm \\
12.13\end{array}$ & 0.099 \\
\hline Age group, n (\%) & & & & 0.078 \\
\hline$>60$ years & $17(12)$ & $13(17)$ & $4(6)$ & \\
\hline$<60$ years & $121(86)$ & $62(82)$ & $59(92)$ & \\
\hline Not reported & $2(1)$ & $1(1)$ & $1(2)$ & \\
\hline Male, n (\%) & $71(51)$ & $37(49)$ & $34(53)$ & 0.723 \\
\hline Medical worker, n (\%) & $1(1)$ & $0(0)$ & $1(2)$ & 0.457 \\
\hline Epidemiological history, n (\%) & & & & 0.236 \\
\hline Traveling to Wuhan & $46(33)$ & $23(30)$ & $23(36)$ & \\
\hline Contact with patients from Wuhan & $8(6)$ & $4(5)$ & $4(6)$ & \\
\hline Contact with other patients & $57(41)$ & $37(49)$ & $20(31)$ & \\
\hline No known epidemiologic risk & $29(20)$ & $12(16)$ & $17(27)$ & \\
\hline $\begin{array}{l}\text { Time From Contact To } \\
\text { Confirmation, Median (IQR) }\end{array}$ & $7(4,12)$ & $7.5(5,14)$ & $6.5(4,9.25)$ & 0.026 \\
\hline Smoking history, n (\%) & $8(6)$ & $7(9)$ & $1(2)$ & 0.07 \\
\hline Drinking, n (\%) & $4(3)$ & $1(1)$ & $3(5)$ & 0.332 \\
\hline \multicolumn{5}{|l|}{ Comorbidities } \\
\hline Hypertension, n (\%) & $36(26)$ & $17(22)$ & $19(30)$ & 0.285 \\
\hline Diabetes mellitus, $\mathrm{n}(\%)$ & $12(9)$ & $6(8)$ & $6(9)$ & 0.648 \\
\hline Chronic kidney disease, n (\%) & $2(1)$ & $2(3)$ & $0(0)$ & 0.166 \\
\hline Chronic liver disease, $\mathrm{n}(\%)$ & $9(6)$ & $4(5)$ & $5(8)$ & 0.134 \\
\hline $\begin{array}{l}\text { Chronic cardiovascular disease, } \mathrm{n} \\
(\%)\end{array}$ & $4(3)$ & $4(5)$ & $0(0)$ & 0.019 \\
\hline Chronic pulmonary disease, n (\%) & $4(3)$ & $2(3)$ & $2(3)$ & 0.368 \\
\hline Malignancy, n (\%) & $2(1)$ & $0(0)$ & $2(3)$ & 0.041 \\
\hline Other comorbidities, n (\%) & $8(6)$ & $5(7)$ & $3(5)$ & 0.36 \\
\hline
\end{tabular}




\begin{tabular}{|c|c|c|c|c|}
\hline \multicolumn{5}{|l|}{ On admission vital signs } \\
\hline Temperature $\left({ }^{\circ} \mathrm{C}\right)$, Median (IQR) & $\begin{array}{l}36.9(36.5 \\
37.4)\end{array}$ & $\begin{array}{l}36.9(36.5 \\
37.23)\end{array}$ & $\begin{array}{l}37(36.65, \\
37.5)\end{array}$ & 0.328 \\
\hline Heart rate (bpm), Mean \pm SD & $\begin{array}{l}90.61 \pm \\
12.35\end{array}$ & $88.11 \pm 11.07$ & $93.59 \pm 13.2$ & 0.009 \\
\hline $\begin{array}{l}\text { Respiratory rate (rpm), Median } \\
\text { (IQR) }\end{array}$ & $20(20,20)$ & $20(20,20)$ & $20(20,20)$ & 0.478 \\
\hline SBP, Median (IQR) & $\begin{array}{l}128(119.5 \\
139)\end{array}$ & $\begin{array}{l}126(117.75, \\
134.25)\end{array}$ & $\begin{array}{l}131(120, \\
147)\end{array}$ & 0.037 \\
\hline$\overline{\mathrm{DBP}}, \mathrm{Mean} \pm \mathrm{SD}$ & $83 \pm 11.36$ & $80.17 \pm 10.76$ & $\begin{array}{l}86.41 \pm \\
11.21\end{array}$ & 0.001 \\
\hline Urine output, Mean \pm SD & $\begin{array}{l}1511.82 \pm \\
707.63\end{array}$ & $\begin{array}{l}1268.57 \pm \\
550.98\end{array}$ & $\begin{array}{l}1937.5 \pm \\
826.01\end{array}$ & 0.213 \\
\hline \multicolumn{5}{|l|}{ Symptoms on presentation } \\
\hline Cough, n (\%) & $114(81)$ & $60(79)$ & $54(84)$ & 0.545 \\
\hline Sputum, n (\%) & $101(72)$ & $51(67)$ & $50(78)$ & 0.208 \\
\hline Rhinorrhea, n (\%) & $11(8)$ & $7(9)$ & $4(6)$ & 0.739 \\
\hline Pharyngalgia, n (\%) & $17(12)$ & $8(11)$ & $9(14)$ & 0.705 \\
\hline Fatigue, n (\%) & $40(29)$ & $20(26)$ & $20(31)$ & 0.648 \\
\hline Myalgia, n (\%) & $8(6)$ & $3(4)$ & $5(8)$ & 0.469 \\
\hline Headache, n (\%) & $19(14)$ & $8(11)$ & $11(17)$ & 0.369 \\
\hline Nausea and vomiting, n (\%) & $20(14)$ & $15(20)$ & $5(8)$ & 0.077 \\
\hline Abdominal pain, n (\%) & $10(7)$ & $7(9)$ & $3(5)$ & 0.345 \\
\hline Diarrhea, n (\%) & $55(39)$ & $26(34)$ & $29(45)$ & 0.244 \\
\hline Dyspnea, n (\%) & $28(20)$ & $17(22)$ & $11(17)$ & 0.581 \\
\hline
\end{tabular}

Abbreviations: ProLOS: prolonged length of stay in hospital; SD: standard deviation; IQR: interquartile range.

\section{Laboratory findings}

Laboratory tests were recorded on the day of hospital admission. Lower lymphocyte count $(1.0[0.7,1.3]$ vs. $1.3[0.9,1.72] \times 109 / L ; p=0.008)$, lower ionized sodium $(136[134.6,137.83]$ vs. $138[135.28,140.03]$ $\mathrm{mmol} / \mathrm{L} ; \mathrm{p}<0.001)$ and higher PaCO2 (40.82 $\pm 3.96 \mathrm{vs} .38 .48 \pm 5.48 \mathrm{mmHg} ; \mathrm{p}=0.007)$ were associated with higher risk of ProLOS. PCT was not associated with ProLOS because most of them (99\%) were within normal range. Other laboratory measurements were not significantly different between the two groups (Table 2).

\section{Table 2. Laboratory findings and comparisons between ProLOS and non-ProLOS groups}




\begin{tabular}{|c|c|c|c|c|}
\hline Variables & $\begin{array}{l}\text { Total }(\mathrm{n}= \\
140)\end{array}$ & $\begin{array}{l}\text { Non-ProLOS } \\
(\mathrm{n} \\
=76)\end{array}$ & $\begin{array}{l}\text { ProLOS }(\mathrm{n}= \\
64)\end{array}$ & $\mathrm{p}$ \\
\hline PCT (ng/ml), Median (IQR) & $\begin{array}{l}0.04(0.02, \\
0.07)\end{array}$ & $\begin{array}{l}0.04(0.02, \\
0.07)\end{array}$ & $\begin{array}{l}0.04(0.02, \\
0.06)\end{array}$ & 0.914 \\
\hline CRP (mg/dl), Median (IQR) & $\begin{array}{l}10(2.9 \\
25.68)\end{array}$ & $\begin{array}{l}8.2(1.67 \\
31.07)\end{array}$ & $\begin{array}{l}11.55(3.6, \\
24.67)\end{array}$ & 0.283 \\
\hline WBC $(\times 109 / L)$, Median (IQR) & $\begin{array}{l}4.6(3.77, \\
5.8)\end{array}$ & $4.9(3.9,6.32)$ & $\begin{array}{l}4.35(3.4, \\
5.62)\end{array}$ & 0.05 \\
\hline $\begin{array}{l}\text { Neutrophil count }(\times 109 / L) \text {, Median } \\
(\mathrm{IQR})\end{array}$ & $3(2.3,3.9)$ & $3.05(2.5,4.1)$ & $2.9(2.2,3.7)$ & 0.17 \\
\hline $\begin{array}{l}\text { Lymphocyte count }(\times 109 / \\
L), \text { Median (IQR) }\end{array}$ & $1.1(0.8,1.6)$ & $1.3(0.9,1.72)$ & $1(0.7,1.3)$ & 0.008 \\
\hline Hematocrit (\%), Mean \pm SD & $40.03 \pm 4.09$ & $39.74 \pm 4.43$ & $40.38 \pm 3.64$ & 0.351 \\
\hline $\begin{array}{l}\text { Hemoglobin }(\mathrm{g} / \mathrm{L}), \text { Mean } \pm \\
\text { SD }\end{array}$ & $\begin{array}{l}135.46 \pm \\
15.22\end{array}$ & $\begin{array}{l}134.72 \pm \\
16.76\end{array}$ & $\begin{array}{l}136.33 \pm \\
13.26\end{array}$ & 0.528 \\
\hline $\begin{array}{l}\text { Platelet count }(\times 109 / L) \text {, Median } \\
\text { (IQR) }\end{array}$ & $\begin{array}{l}182(150.75 \\
228.5)\end{array}$ & $\begin{array}{l}182.5(151.5 \\
243)\end{array}$ & $\begin{array}{l}\text { 181(150.75, } \\
214)\end{array}$ & 0.441 \\
\hline PT, Mean \pm SD & $12.71 \pm 1.15$ & $12.45 \pm 1.06$ & $13.03 \pm 1.2$ & 0.003 \\
\hline APTT, Mean \pm SD & $30.83 \pm 3.27$ & $30.3 \pm 2.91$ & $31.47 \pm 3.59$ & 0.041 \\
\hline $\begin{array}{l}\text { D-dimmer (ng/ml), Median } \\
\text { (IQR) }\end{array}$ & $134(89,188)$ & $\begin{array}{l}138(87.5 \\
219)\end{array}$ & $\begin{array}{l}124(96.5 \\
162.25)\end{array}$ & 0.441 \\
\hline $\begin{array}{l}\text { Fibrinogen (g/L), Median } \\
\text { (IQR) }\end{array}$ & $\begin{array}{l}3.72(3.1 \\
4.13)\end{array}$ & $\begin{array}{l}3.68(3.12, \\
4.19)\end{array}$ & $\begin{array}{l}3.72(3.11, \\
4.11)\end{array}$ & 0.537 \\
\hline Albumin (g/L), Mean \pm SD & $41.94 \pm 4.05$ & $41.48 \pm 4.44$ & $42.49 \pm 3.49$ & 0.133 \\
\hline $\begin{array}{l}\text { Globulin (g/L), Median } \\
\text { (IQR) }\end{array}$ & $\begin{array}{l}28.65(26.4, \\
31.13)\end{array}$ & $\begin{array}{l}28.05(26.35, \\
30.6)\end{array}$ & $\begin{array}{l}28.75(27.4 \\
32.25)\end{array}$ & 0.102 \\
\hline ALT (U/L), Median (IQR) & $22(13,32.5)$ & $\begin{array}{l}18.5(12.75 \\
32)\end{array}$ & $22.5(15,36)$ & 0.227 \\
\hline AST, Median (IQR) & $24(19,34)$ & $23(18,31.5)$ & $\begin{array}{l}27(20.75, \\
34.5)\end{array}$ & 0.085 \\
\hline $\begin{array}{l}\text { Total bilirubin }(\mu \mathrm{mol} / \mathrm{L}), \text { Median } \\
\text { (IQR) }\end{array}$ & $\begin{array}{l}11.95(8.67, \\
15.9)\end{array}$ & $\begin{array}{l}12.3(9.28 \\
16.47)\end{array}$ & $\begin{array}{l}10.8(8.38, \\
15.6)\end{array}$ & 0.344 \\
\hline $\begin{array}{l}\text { Direct bilirubin }(\mu \mathrm{mol} / \mathrm{L}), \text { Median } \\
\text { (IQR) }\end{array}$ & $4.5(3.2,6.1)$ & $\begin{array}{l}4.65(3.38 \\
6.32)\end{array}$ & $\begin{array}{l}4.05(3.08, \\
5.9)\end{array}$ & 0.22 \\
\hline $\begin{array}{l}\text { BUN (mmol/L), Median } \\
\text { (IQR) }\end{array}$ & $\begin{array}{l}3.65(3.1, \\
4.23)\end{array}$ & $3.75(3,4.6)$ & $3.6(3.1,4.03)$ & 0.358 \\
\hline
\end{tabular}

Abbreviations: SD: standard deviation; IQR: interquartile range; PCT: procalcitonin; ALT: Alanine Aminotransferase; AST: Aspartate Aminotransferase; TB: total bilirubin; CKMB: Creatine Kinase Myocardial Band; CK: Creatine Kinase; PT: partial thrombin time; APTT: activated partial thrombin time; WBC: white blood count; LDH: Lactate Dehydrogenase.

\section{Complications and outcomes}

Seven patients (5\%) developed respiratory failure and one patient (1\%) had acute respiratory failure during hospital stay. Seventy-five (54\%) patients required oxygen therapy via nasal tube, 7 patients (5\%) required facial mask, and 4 patients $(3 \%)$ required non-invasive mechanical ventilation. The median time from hospital admission to the first negative nucleic acid test was 13 days ( 7.25 to 17 days), and the 
second negative nucleic acid test was 15.5 days (10 to 19 days). Of note, two patients showed second positive nucleic acid test after negative nucleic acid tests. There were $4(3 \%)$ critically and $5(4 \%)$ severely ill patients (Table 3 ).

\section{Table 3. Complications and outcomes of the overall population and comparisons between ProLOS and non-ProLOS groups}

\begin{tabular}{|l|l|l|l|l|}
\hline Variables & $\begin{array}{l}\text { Total }(\mathrm{n}= \\
140)\end{array}$ & $\begin{array}{l}\text { Non-ProLOS } \\
(\mathrm{n}=76)\end{array}$ & $\begin{array}{l}\text { ProLOS }(\mathrm{n}= \\
64)\end{array}$ & $\mathrm{p}$ \\
\hline Respiratory failure, n (\%) & $7(5)$ & $5(7)$ & $2(3)$ & 0.454 \\
\hline Liver injury, n (\%) & $2(1)$ & $0(0)$ & $2(3)$ & 0.207 \\
\hline $\begin{array}{l}\text { Oxygen therapy via nasal canula, } \\
\mathrm{n}(\%)\end{array}$ & $75(54)$ & $35(46)$ & $40(62)$ & 0.076 \\
\hline Facial mask, n (\%) & $7(5)$ & $5(7)$ & $2(3)$ & 0.454 \\
\hline $\begin{array}{l}\text { Non-invasive mechanical } \\
\text { ventilation, n (\%) }\end{array}$ & $4(3)$ & $3(4)$ & $1(2)$ & 0.625 \\
\hline $\begin{array}{l}\text { Fist negative nucleic acid test } \\
\text { day, Median (IQR) }\end{array}$ & $13(7.25,17)$ & $8.5(4,12)$ & $18.5(15,20)$ & $<$ \\
\hline $\begin{array}{l}\text { Second negative nucleic acid test } \\
\text { day, Median (IQR) }\end{array}$ & $15.5(10,19)$ & $12(6.25,15)$ & $\begin{array}{l}21(18, \\
21.75)\end{array}$ & 0.001 \\
\hline Severity, n (\%) & & & & 0.001 \\
\hline Critical & $4(3)$ & $3(4)$ & $1(2)$ & \\
\hline Mild & $131(94)$ & $71(93)$ & $60(94)$ & \\
\hline Severe & $5(4)$ & $2(3)$ & $3(5)$ & \\
\hline Mortality, n (\%) & & & & 0.032 \\
\hline Alive & $63(45)$ & $41(54)$ & $22(34)$ & \\
\hline Follow & $77(55)$ & $35(46)$ & $42(66)$ & \\
\hline Hospital LOS, Median (IQR) & $19.52(16.44$, & $16.51(11.52$, & $25.41(22.6$, & $<$ \\
& $24.55)$ & $18.29)$ & $27.76)$ & 0.001 \\
\hline HosLOS20, n (\%) & & & & $<$ \\
\hline
\end{tabular}

Abbreviations: SD: standard deviation; IQR: interquartile range; LOS: length of stay.

Model selection with stepwise procedure resulted in a model with 7 predictors including age, time from contact to confirmation, DBP, lymphocyte count, AST, ionized sodium, PaCO2. These predictors were obtained on hospital admission (Table 4). The model was well calibrated and had a good prediction discrimination with an AUC of $81.6 \%$ (95\% Cl: $74.4 \%$ to $88.8 \%$, Figure 1). The model could be used with a nomogram (Figure 2).

\section{Table 4 Prediction model established by using stepwise model selection}




\begin{tabular}{|l|l|l|}
\hline Predictors & OR [95\% CI] & $\mathrm{p}$ \\
\hline Age (with each year increase) & $0.95[0.91,0.99]$ & 0.008 \\
\hline Time From Contact To Confirmation (with each day increase) & $0.92[0.85,0.99]$ & 0.040 \\
\hline DBP (with each 1 mmHg increase) & $1.06[1.02,1.10]$ & 0.004 \\
\hline Lymph Count (with each $1 \times 109 / L$ increase) & $0.30[0.13,0.66]$ & 0.004 \\
\hline AST (with each 1 IU/L increase) & $1.02[1.00,1.05]$ & 0.056 \\
\hline Sodium (with each 1 mmol/L increase) & $0.88[0.76,0.97]$ & 0.029 \\
\hline PaCO $_{2}$ (with each 1 mmHg increase) & $1.15[1.06,1.27]$ & 0.002 \\
\hline
\end{tabular}

Abbreviations: DBP: diastolic blood pressure; AST: Aspartate Aminotransferase.

\section{Discussion}

The study described clinical characteristics of COVID-19 outside Wuhan. The results showed that the prevalence of severe and critical cases was low, and there was no patient died during the follow up. This is an important feature of COVID-19 outside of Wuhan city. Initial reports from Wuhan showed that 17$29 \%$ patients developed acute respiratory distress syndrome and $11-12 \%$ died of multiple organ failure 4,5 . However, the high mortality rate was only observed in Wuhan. A nationwide multicenter study showed that $5 \%$ patients required ICU admission and the overall mortality rate was $1.36 \%{ }^{19}$. Similarly, Studies from Zhejiang province reported that the prevalence of severe cases was very low and no death was reported ${ }^{11,20}$. The large difference in disease severity between Wuhan and other cities may reflect the shortage of medical resources in Wuhan when large number of cases emerged.

The median time from contact with infection source to case confirmation was 7 days. The median incubation period was reported to be 3 days (Range: 0 to 24 days) ${ }^{19}$. It generally takes a couple of days for a patient be hospitalized after symptom onset. Thus, the median time from contact with infection source and case confirmation was 7 days (IQR: 4 to 12 days) in our cohort. To the best of our knowledge, there has been no study reporting the time for negative conversion of the nucleic acid test. Our study showed that it might take a median of 13 days for nucleic acid test to become negative. However, it should be noted that there were two cases whose second nucleic acid test return positive following the first negative test, which highlighted the importance of multiple nucleic acid tests before hospital discharge.

Our study for the first time developed a risk stratification tool for the prediction of ProLOS for a cohort with mild illness. The discrimination and calibration of the model was good. The predictors in the model were routinely available in clinical practice. Sophisticated stepwise model selection procedure was performed with the aim to minimize the AIC value ${ }^{21}$. The model aimed to improve the predictive accuracy while keeping the number of predictors at a minimum level (i.e. the principle of parsimony).

Several limitations must be acknowledged in the study. First, the study was performed in a single center, and the external validity of the findings was not known ${ }^{22}$. As has been discussed above, there was large difference between our cohort and studies from Wuhan. Since studies from outside Wuhan are still rare, more studies can be performed to elucidate the reasons underlying the disparity. Second, although our 
prediction model showed good discrimination and calibration in internal validation, it lacks external validation. In other words, the model carries the risk of overfitting ${ }^{23}$. However, we have tried to minimize the problem of overfitting. The criteria for model selection also considered the degree of freedom, which helped to control the overfitting problem. Third, the majority of patients in our study was mild, and the risk stratification tool may not be applicable to severe or critical cases. For example, older age was identified as a protective factor for ProLOS, which is in contrast to the current knowledge that older age is a risk factor for adverse clinical outcome ${ }^{24}$. Probability, patients in our study were not very old and comorbidity burden was very low. The adverse effect of older age is mediated via increased comorbidity burden. With low comorbidity burden, the mediation pathway was blocked and the casual linkage between age and adverse outcome was also changed.

In conclusion, our study described clinical characteristics of COVID-19 outside of Wuhan. The major difference of COVID-19 in other cities included low comorbidity burden, low prevalence of severe or critical cases and low mortality rate. Furthermore, we developed a multivariate regression model to predict the risk of ProLOS, which showed good discrimination and calibration.

\section{Reference}

1. Kickbusch, I. \& Leung, G. Response to the emerging novel coronavirus outbreak. $B M J \mathbf{3 6 8}, \mathrm{m} 406$ (2020).

2. Wu, S. S. et al. Epidemiological Development of Novel Coronavirus Pneumonia in China and Its Forecast. medRxiv 02.21.20026229 (2020).

3. Wu, Z. \& McGoogan, J. M. Characteristics of and Important Lessons From the Coronavirus Disease 2019 (COVID-19) Outbreak in China: Summary of a Report of 72314 Cases From the Chinese Center for Disease Control and Prevention. JAMA (2020). doi:10.1001/jama.2020.2648

4. Chen, N. et al. Epidemiological and clinical characteristics of 99 cases of 2019 novel coronavirus pneumonia in Wuhan, China: a descriptive study. Lancet (2020). doi:10.1016/S0140-6736(20)302117

5. Huang, C. et al. Clinical features of patients infected with 2019 novel coronavirus in Wuhan, China. Lancet (2020). doi:10.1016/S0140-6736(20)30183-5

6. Li, Z. et al. Caution on Kidney Dysfunctions of 2019-nCoV Patients. medRxiV2020.02.08.20021212 (2020).

7. Chen, et al. [Analysis of clinical features of 29 patients with 2019 novel coronavirus pneumonia]. Zhonghua Jie He He Hu Xi Za Zhi 43, E005-E005 (2020).

8. Wang, D. et al. Clinical Characteristics of 138 Hospitalized Patients With 2019 Novel CoronavirusInfected Pneumonia in Wuhan, China. JAMA (2020). doi:10.1001/jama.2020.1585

9. Zhou, L. \& Liu, H. G. [Early detection and disease assessment of patients with novel coronavirus pneumonia]. Zhonghua Jie He He Hu Xi Za Zhi 43, E003-E003 (2020). 
10. An, P. et al. Clinical Features of 2019 Novel Coronavirus Pneumonia Presented Gastrointestinal Symptoms But Without Fever Onset. (2020).

11. Xu, X.-W. et al. Clinical findings in a group of patients infected with the 2019 novel coronavirus (SARS-Cov-2) outside of Wuhan, China: retrospective case series. BMJ 368, m606 (2020).

12. Novel Coronavirus Pneumonia Emergency Response Epidemiology Team. [The epidemiological characteristics of an outbreak of 2019 novel coronavirus diseases (COVID-19) in China]. Zhonghua Liu Xing Bing Xue Za Zhi 41, 145-151 (2020).

13. Sun, K., Chen, J. \& Viboud, C. Early epidemiological analysis of the 2019-nCoV outbreak based on a crowdsourced data. medRxiv 01.31.20019935 (2020).

14. Elm, von, E. et al. The Strengthening the Reporting of Observational Studies in Epidemiology (STROBE) statement: guidelines for reporting observational PLoS medicine 4, e296 (2007).

15. Jin, Y.-H. et al. A rapid advice guideline for the diagnosis and treatment of 2019 novel coronavirus (2019-nCoV) infected pneumonia (standard version). Mil Med Res 7, 4-23 (2020).

16. Zhang, Z., Gayle, A. A., Wang, J., Zhang, H. \& Cardinal-Fernández, P. Comparing baseline characteristics between groups: an introduction to the CBCgrps package. Ann Trans/ Med 5, 484484 (2017).

17. Harrell, F. E. Regression Modeling Strategies. (Springer New York, 2001). doi:10.1007/978-1-47573462-1

18. Zhang, Z. \& Kattan, M. W. Drawing Nomograms with R: applications to categorical outcome and survival data. Ann Transl Med 5, 211-211 (2017).

19. Guan, W.-J. et al. Clinical characteristics of 2019 novel coronavirus infection in China. medRxiv 2020.02.06.20020974 (2020).

20. Qian, G.-Q. et al. Epidemiologic and Clinical Characteristics of 91 Hospitalized Patients with COVID19 in Zhejiang, China: A retrospective, multi-centre case medRxiv 2020.02.23.20026856 (2020).

21. Zhang, Z. Variable selection with stepwise and best subset approaches. Ann Trans/ Med 4, 136-136 (2016).

22. Riley, R. D. et al. External validation of clinical prediction models using big datasets from e-health records or IPD meta-analysis: opportunities and challenges. BMJ 353, i3140 (2016).

23. Zhang, Z. Too much covariates in a multivariable model may cause the problem of overfitting. $J$ Thorac Dis 6, E196-7 (2014).

24. Villar, J. et al. Age, PaO2/FIO2, and Plateau Pressure Score: A Proposal for a Simple Outcome Score in Patients With the Acute Respiratory Distress Syndrome. Care Med. 44, 1361-1369 (2016).

\section{Figures}




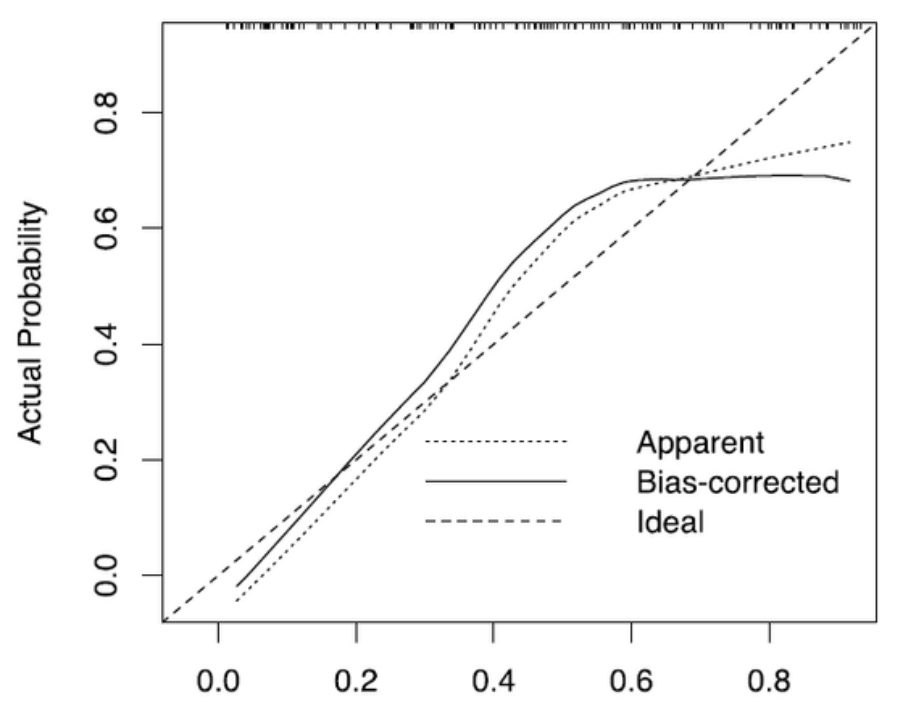

Predicted Probability of hospital LOS $>20$ days $B=40$ repetitions, boot Mean absolute error $=0.074 n=136$

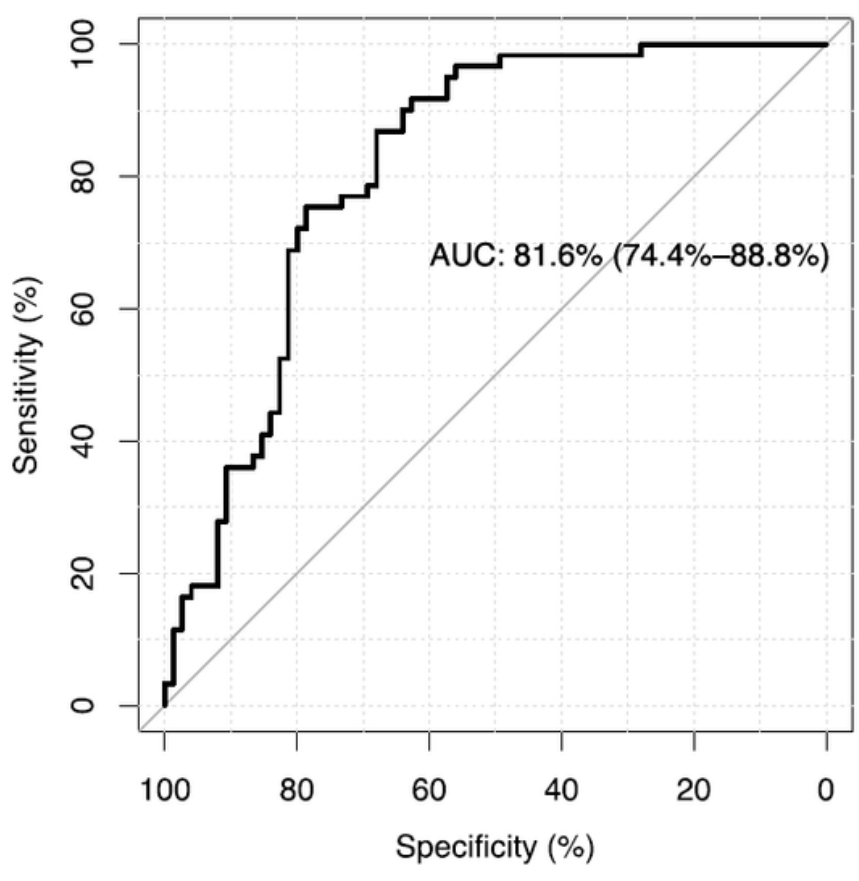

\section{Figure 1}

Model calibration and discrimination. 
Points

Nomogram for Prediction of hospital LOS>20 days

$\mathrm{PaCO} 2^{\star \star}$

Sodium*

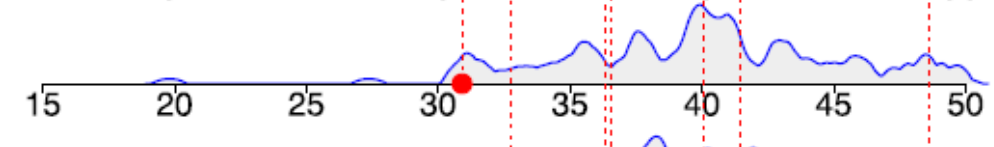

AST

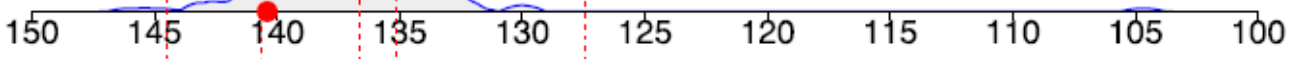

LymphCount**

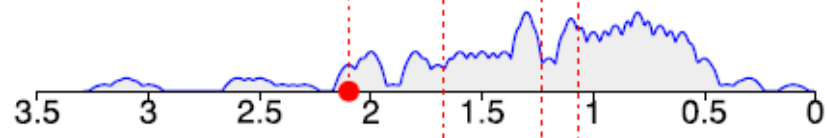

$\mathrm{DBP}^{* \star *}$

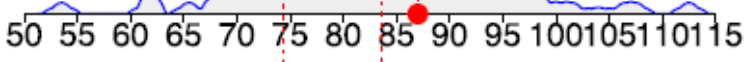

FromContactToConf*

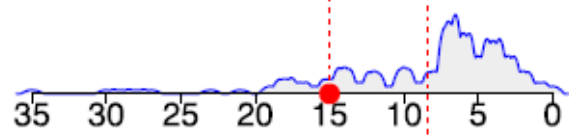

Age $^{\star *}$

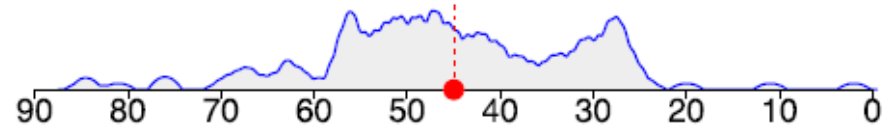

Total points

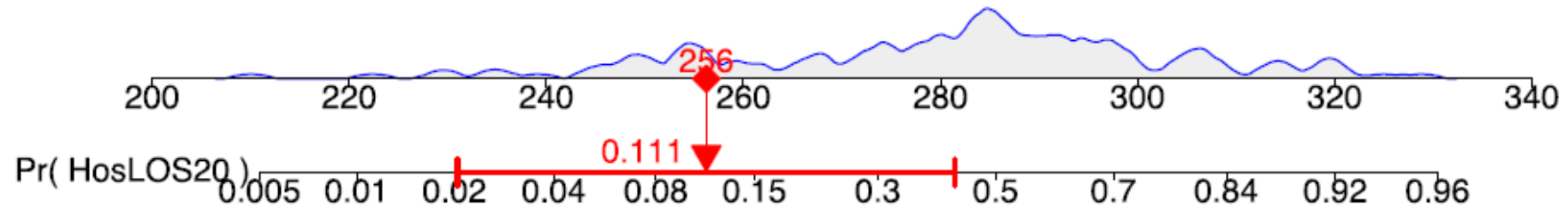

Figure 2

Nomogram demonstrating the use of the risk stratification tool. 